\title{
Performance evaluation for Egyptian's Computers and Information Faculties: Using a Stochastic Input Oriented Data Envelopment Analysis Model
}

\author{
Basma E. El-Demerdash \\ Lecturer Assistant, Department \\ of Operations Research and \\ Decision Support, Faculty of \\ Computers and Information, \\ Cairo University, Egypt
}

\author{
Ihab A. El-Khodary \\ Associate Professor, \\ Department of Operations \\ Research and Decision Support, \\ Faculty of Computers and \\ Information, Cairo University, \\ Egypt
}

\author{
Assem A. Tharwat \\ Professor, Academic Vice \\ President of The Higher \\ Canadian International College \\ for Engineering and Business, \\ Canadian International College, \\ Egypt
}

\begin{abstract}
Data Envelopment Analysis (DEA) is a great approach used for measuring relative efficiencies and performance of a collection of Decision Making Units (DMUs). These used in the various forms, such as hospitals, universities, air force, banks, courts, business firms, and others, including the performance of countries, regions, etc. One of the earliest applications of DEA called Education. It was an ideal introduction for DEA because it typically deals with comparisons of many similar and autonomous 'non-profit' entities described by inputs and outputs. Therefore, education served to test and validate DEA as a tool for analysis and decision support. Recently DEA has been extended to examine the efficiency of Higher Education operations. In this paper, a Stochastic Input Oriented Data Envelopment Analysis (SIODEA) Model is conducted for the comparison of evaluating the relative efficiency scores of Faculties of Computers and Information (FCIs) each with some of inputs are stochastic with normally distributed, recent inputs are deterministic and outputs.
\end{abstract}

\section{Keywords}

Stochastic Data Envelopment Analysis; Higher Education; Stochastic Variables; Evaluating Performance; Efficiency Measurement.

\section{INTRODUCTION}

Measuring the efficiency of the Higher Education Institutions (HEIs) have become an important and appealing research area in recent years. These institutions are always under stress to discuss and communicate clear priorities and focus on efficient management, planning and resource processes to achieve excellence and ensure continuous performance improvement. One of the major roles of HEIs is scientific research. Obviously, the scientific research plan for the HEI should be influenced by motivated to sustainability with the goal of inventing new methods to deal with all the major problems facing mankind such as infectious diseases, pollution, energy, unemployment, etc. However the most important impact of HEIs is in education. Whatever specific topic is being taught the question whether and how it may influence development towards sustainability must always be asked and discussed.

Higher education is considered to have a great influence on the economy in many ways. Most importantly, it affects the stock of human with attention to both private and social rates of return to graduates. Also, higher education plays an important role on the social and cultural environments, which in turn has influence on the economic environment within which businesses operate [1].

From the above discussion it is evident that HEIs have an important role to play in the well-being of the society. When performing efficiently they have a direct impact on the economy which also translates into the well-being of the society. Therefore, HEIs are requested to continuously monitor their performance and to directly compare the efficiency of their performance against a peer or combination of peers of other HEIs and thus determine where they stand among other HEIs. Accordingly, it would be of interest that if the HEI is inefficient, to determine the possible sources of deficiencies. Based on these deficiencies/weaknesses the institute would be able to formulate a future plan in order to overcome these deficiencies and enhance the performance. With this thought in mind, it is necessary to apply a tool that is capable of measuring the efficiency of each HEI, especially public HEIs. Public HEIs are "non-profit" organizations that produce multiple outputs by utilizing multiple inputs having different units; therefore the selected tool should be able to accommodate these conditions.

The DEA technique is considered the most appropriate tool for evaluating the performance of HEIs under the aforementioned conditions. It is a non-parametric method in operations research based on fractional programming for measuring the relative efficiencies of a collection of related comparable entities in transforming inputs into outputs. The objective in this paper is evaluates and compares the relative efficiency scores of Faculties of Computers and Information using an SIODEA Model.

The rest of the paper is organized as follows. The coming section investigates some DEA applications in education. The third section discusses the methodology of stochastic input oriented DEA. The fourth section includes the Egyptian's FCIs case study. The paper will end with the customary conclusions.

\section{LITERATURE REVIEW}

In recent years, several studies have undertaken analysis of efficiency in educational facilities using the DEA methodology. In the coming few paragraphs will discuss a few these DEA applications. Each study differs in its scope; meaning the definitions of DMUs being subject to analysis. Some defined the DMU as being the universities, or specifically confined it to public universities, while others referred to departments within HE faculties. 
Among those who attempted to measure the efficiency among universities, Athanassopoulos and Shale [2] examined the comparative of 45 universities in the UK using DEA method. $\mathrm{Chu}$ and $\mathrm{Li}$ [3] used DEA algorithm to examine the effectiveness of the 84 key Chinese higher education institutions in the mid-1980s in China. Avkiran [4] examined the relative efficiency of Australian universities using DEA approach. Abbott and Doucouliagos [5] used DEA to estimate technical and scale efficiency of individual Australian universities. Taylor and Harris [6] used the DEA technique to examine the relative efficiency of South African universities between 1994 and 1997, based on a sample of ten of the country's 21 public universities. Duh and Kuo [7] used DEA to examine the effect of the amendment of an education-related law on university efficiency using the 1994 University Law amendment in Taiwan. Worthington and Lee [8] used DEA to investigate the productivity growth in 35 Australian universities over the period 1998-2003. Afonso and Santos [9] applied the DEA approach to estimate the efficiency scores for Portuguese public universities. Johnes and Yu [10] applied the DEA on 109 Chinese public universities in 2003 and 2004. Agasisti and Perez-Esparrells [11] used DEA model to compare the efficiency of Italian and Spanish state universities. Awadz, Azlina Shaikh, et al. [12] used DEA approach to explore the performance efficiency of faculties at a Malaysian university.

At the departmental level, Stern et al. [13] used DEA technique to examine the relative efficiency of 21 academic departments in Ben-Gurion University at Israel. Johnes et al. [14] used DEA method to investigate the technical efficiency of U.K. university departments of economics as producers of research. Lopes and Lanzer [15] addressed the issue of performance evaluation of academic departments at a University using a DEA model which used to simulate a process of cross-evaluation between departments. Martín [16] applied the DEA methodology to assess the performance of departments at the University of Zaragoza (Spain). Köksal and Nalsaci [17] studied the relative efficiency of departments in Turkish engineering universities using DEA model. Kao and Hung [18] used DEA to assess the relative efficiency of 41 academic departments at National Cheng Kung University in Taiwan. Tyagi et al. [19] applied DEA to evaluate the performance efficiencies of 19 academic departments of IIT Roorkee (India).

In all the previous applications, and to our knowledge, in most of the DEA applications related to higher education, the DEA applied in measuring the efficiency was deterministic, i.e. the input and output variables are deterministic in nature. This is not necessarily true for all variables, some of these variables could be random by nature. In this research are looking forward applying the stochastic DEA in the higher education sector.

\section{METHODOLOGY}

DEA is developed by Charnes et al. [20] and extended by Banker et al. [21]. It is used for measuring efficiency in the cases where multiple input and output factors are observed and when it is not possible to turn these into one aggregate input or output factor. The DEA methodology is especially adequate to evaluate the efficiency of non-profit entities that operate outside the market, since for them performance indicators, such as income and profitability, do not work satisfactorily. El-Demerdash et al. [22] modified the standard DEA model to measure the relative efficiency in the presence of random variation in some of inputs from given outputs. In the Chance Constrained Input Oriented DEA Model, the outputs are assumed to be deterministic while some of inputs are random variables and remaining inputs are deterministic variables, each input $x_{j}, j \in J_{S}$ is normally distributed with mean $\mu_{p}$ and variance $\sigma_{p}^{2}$ and the relation between the same stochastic input variable through different DMUs is dependent, this means $\operatorname{cov}\left(x_{i}, x_{p}\right) \neq 0$.. The chanceconstrained DEA model builds on the method of CCP and is as showed below:

$$
\operatorname{Min} Z_{p}=\theta
$$

s.t.

$$
\begin{aligned}
& \sum_{i=1}^{n} \lambda_{i} \mu_{i}-\theta \mu_{p} \\
& \leq e \sqrt{\sum_{\substack{i=1 \\
i \neq p}}^{n} \lambda_{i}^{2} \sigma_{i}^{2}+\left(\lambda_{p}-\theta\right)^{2} \sigma_{p}^{2}+2 \operatorname{cov}\left(x_{i}, x_{p}\right)}, \forall j=1, \ldots J_{S} \\
& \sum_{i=1}^{n} \lambda_{i} x_{i} \leq \theta x_{p}, \quad \forall j=1, \ldots \ldots . J_{D} \\
& \sum_{i=1}^{n} \lambda_{i} y_{i} \geq y_{p}, \quad \forall k=1, \ldots \ldots . m \\
& \sum_{i=1}^{n} \lambda_{i}=1 \\
& \lambda_{i} \geq 0,(i=1,2, \ldots, n)
\end{aligned}
$$

\section{PERFORMANCE EVALUATION FOR} FCIs

In Egypt, as for the rest of the world, there has been an interest in increasing the efficiency of the HEIs. Most of the HEIs are public and "non-profit" organizations, most of the previous DEA applications in the HE, DMUs were deterministic in their inputs and outputs, although some of the input variables may have a random nature. So this section will be a road way plan of how can measure the relative efficiency using the developed model for FCIs across public Egyptian universities, taking into consideration that some input variables are stochastic.

\subsection{Data Collection}

Based on the study of the factors that affect the HEIs, which has been performed through DEA applications in Higher Education Sector and the nature of the Egyptian Universities, the authors managed to determine the variables that need to be addressed. Unfortunately data for those variables is not readily available; therefore to capture the necessary data designed a questionnaire.

The questionnaire identifies the main input and output variables on which the analyses will be based and that are of relevance for the public Egyptian Universities. The main input variables were divided into several categories where each category consists of a number of questions. These input categories include vision, mission, strategic plan and objectives, programs and courses structure, courses evaluation and policies, faculty workforce, students either undergraduate or postgraduate, infrastructure, library and internet service. On the other hand, the output variables were divided among publications and research productivity of academic staff, 
electronic courses produced, number of undergraduate students enrollment, number of graduate students, number of applied graduation projects, and number of awarded postgraduate degrees.

Based on the study aim, sent out the questionnaire by mail to all FCIs across public Egyptian universities (a total of 10 faculties), then followed up on the questionnaires by telephone over a period of two months and a visit to collect the data. As a result, seven out of ten faculties (70\%) was managed to collect data.

\subsection{Data Analysis}

Given the data collected for the FCIs, it is necessary to study this data in order to have a better understanding for these DMUs and to identify the similarities and differences between the DMUs. This could help us later to interpret the results and identify why some of the faculties could be inefficient. The section in hand will highlight some of the major similarities and differences.

Table 1 shows that the ratio between the different faculty workforce categories (academic staff, teaching assistants) and undergraduate students. The authors compared these ratios with the NORMS ratios which are 1: 25 for academic staff, 1: 15 for teaching assistants. It is evident that, for the academic staff ratio one out of seven DMUs does satisfy NORMS ratio. On the other hand for the teaching assistants ratios, it is evident that DMU3, DMU6, and DMU7 do satisfy NORMS ratio, DMU1 and DMU4 are slightly above the ratio, and DMU2 and DMU5 are far from the NORMS ratio. This means that DMU2 and DMU5 have a big problem in the number of teaching assistants.

Table 1. Ratio between types of faculty, workforce and undergraduate students

\begin{tabular}{|c|c|c||}
\hline \# of Student per & $\begin{array}{c}\text { Academic } \\
\text { Staff }\end{array}$ & Teaching Assistants \\
\hline Norms & 25 & 15 \\
\hline DMU1 & 38.6 & 19.3 \\
\hline DMU2 & 56.9 & 56.9 \\
\hline DMU3 & 26.7 & 12.8 \\
\hline DMU4 & 149.3 & 19.6 \\
\hline DMU5 & 51.4 & 45 \\
\hline DMU6 & 17.5 & 8 \\
\hline DMU7 & 60.1 & 13.9 \\
\hline
\end{tabular}

Figure 1 shows the number of undergraduate, postgraduate for the academic year 2010/2011. The figure illustrates that there is high variation in the number of different categories of students across the DMUs. A closer look at the figure 2 reveals the following:

DMU1 and DMU7 have the highest number of undergraduate students and DMU3 and DMU6 have the lowest.

DMU3 and DMU6 have no postgraduate students; DMU1 has the highest number of postgraduate students and the remaining DMUs have contributed a low proportion.

Therefore, notice that DMUs 3 and 6 are relatively smaller than the other faculties considered in this study.

Figure 2 illustrates that for lecture halls in all DMUs can accommodate a large number of students than computer labs.
On the other hand, when compered the total numbers vs. the total capacities of computer labs, it is clear that for all DMUs except DMU1, total areas of computer labs are small. On the contrary, when compered the total numbers vs. the total capacities of lecture halls, it is clear that for all DMUs total areas of lecture halls are appropriate.

The internet service coverage to the academic staff, students, and in computer labs is provided in figure 6.5. The figure reveals that:

- All academic staff in six DMUs have internet service availability, while for DMU3 only $80 \%$ of the staff has internet services;

- DMUs 1, 5, 6, and 7 provide internet services to all students through the $\mathrm{Wi}-\mathrm{Fi}$; and

- All computer labs in all DMUs are connected to the internet.

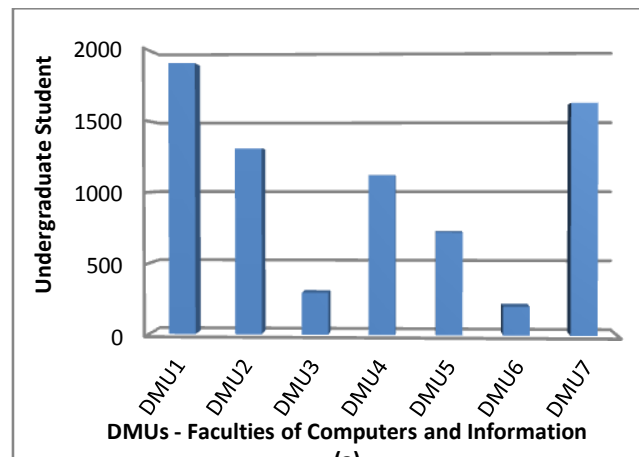

(a)

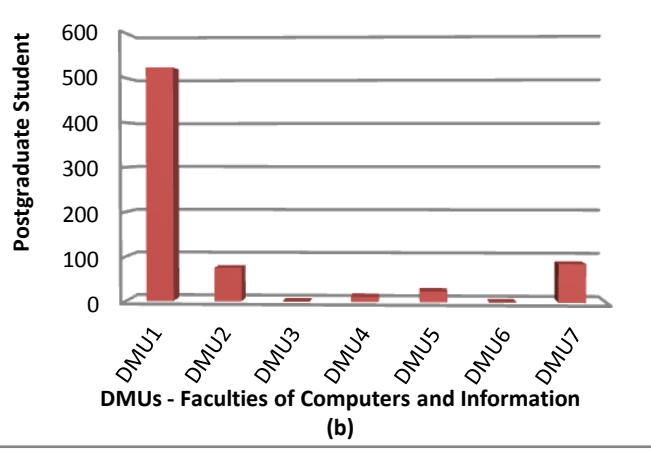

Figure 1 Numbers of students by category

This means that most of DMUs have a good coverage to Internet service availability for academic staff, students, and computer labs.

Given that the data collected will be used to evaluate the relative efficiency and based on the above analyses, the authors were forced to eliminate some of variables because either the data were equal across the variable, some variables had missing data, or some data made no sense (e.g. defined a vision, mission, strategic objectives, and a strategic plan for their respective faculties, number of administrators, internet services, and the research productivity for the academic staff). Accordingly, the authors decided to evaluate and compare the relative efficiency of the educational process for the FCIs based on the number of number of research scientific books, lecture halls capacity, and computer labs capacity for input variables, number of academic staff, number of postgraduate students for stochastic input variables and number of awarded postgraduates (awarded theses), and number of undergraduate student enrollment for output variables. 


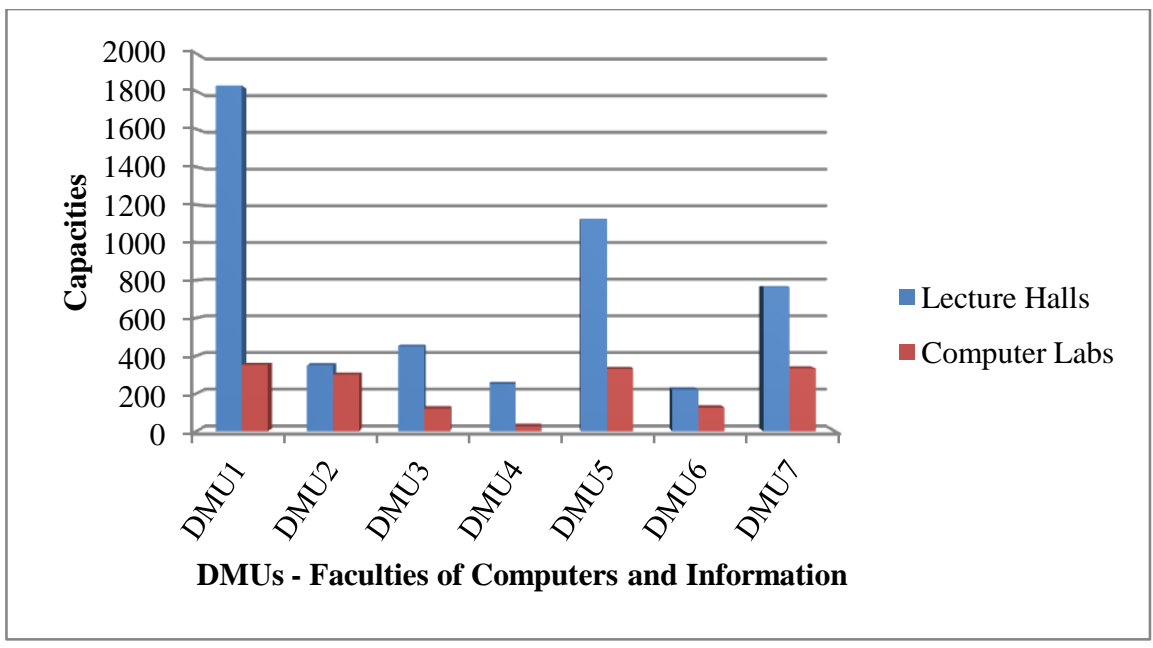

Figure 2 Total capacities of lecture halls and computer labs

\subsection{Scenarios Analyses}

Given the collected data, the next step was to apply the developed SIODEA model in order to measure the relative efficiency of producing certain outputs for a number of DMUs according to relevant input variables (individually or in combinations). In the analyses considered all DMUs, unless a certain DMU has zero output for a particular variable and in such case the DMU(s) will be eliminated. Therefore, the authors settled upon two different scenarios for two different outputs which are graduated students and awarded theses.

For each output variable, it was necessary to select the appropriate input variables that directly result in its production. Therefore, the input variables for the different output variables are shown in Table 2.

Table 2. Outputs variables with appropriate inputs variables

\begin{tabular}{|c|c|}
\hline Outputs & Inputs \\
\hline $\begin{array}{l}\text { Undergraduate Students } \\
\text { Enrollment (USE) }\end{array}$ & $\begin{array}{ll}- & \text { Academic Staff (AS) } \\
- & \text { Computer Labs Capacity } \\
& \text { (CLC) } \\
- & \text { Lecture Halls Capacity } \\
& (\text { LHC) }\end{array}$ \\
\hline Awarded Theses (AT) & $\begin{array}{ll}- & \text { Academic Staff (AS) } \\
\text { - } & \text { Postgraduate Students (PS) } \\
\text { - } & \text { Research Scientific books } \\
& (\mathrm{RSB})\end{array}$ \\
\hline
\end{tabular}

General Algebraic Modeling System (GAMS) language software, version 23.7.1. was used for solving the DEA models. GAMS was chosen for this task since it is capable of handling the non-linearity of the developed model through the integrated high-performance solvers

Below we will provide the analyses for each scenario. Each scenario was split into three sets of sub-scenarios according to the following: first set, each input variable was compared individually with the output; second set, some combinations of the inputs was compared with the output; and finally the third set, where all the inputs were compared with the output.

\subsubsection{Scenario I: Graduated Students}

In this scenario selected three input variables (AS, CLC and LHC) that consider have direct impact on the resulting number of USE. Accordingly, a total of seven sub-scenarios were created for this output divided into the three sets. The first set included three sub-scenarios were the efficiency of the number of USE is investigated against each input independently. The second set also consisted of three different sub-scenarios which were constructed through taking combinations of two input variables (AS and CLC, AS and LHC, and CLC and LHC). The final sub-scenario was a single model which included all three input variables. The results of these sub-scenarios are presented in following table (Table 3).

Based on the analysis of the first set of subscenarios USE1, USE2 and USE3, found that after a closer look at the efficiencies obtained through these as follows:

- DMU1 and DMU6 are efficient in USE2 and USE3 but DMU1 is most likely to reach efficiency and DMU6 is far from efficiency in USE1;

- DMU2, DMU4 and DMU7 are efficient in USE3, DMU2 and DMU4 are likely to approach efficiency, but DMU7 is most remote to the efficiency in USE1 and USE2;

- DMU3 and DMU5 are inefficient in all three cases.

Preforming sensitivity analysis revealed that in order to improve the performance of the DMUs such that they reach the highest efficiency, it is recommended that for USE1, to increase the number of undergraduate students enrolled for DMU3, DMU6, and DMU7 to 435, 470, 2000 students, respectively, so that they would have a relative efficiency equivalent to that of DMU1. On the other hand, for DMU2, DMU4 and DMU5, it is not realistic to improve their relative efficiency by reducing the number of USE, rather it is recommended to increase the number of academic staff. In case of USE2, it is recommended to increase the number of USE for DMU2, DMU3, DMU4, DMU5 and DMU7 to 1830, $500,2000,1300$ and 2000 students, respectively. As for USE3, we can increase the number of enrolled undergraduate students to 1500 for DMU3 and 1800 for DMU5 
Table 3. Relative efficiencies for the number of Undergraduate Students Enrolment

\begin{tabular}{||c|c|c|c|c|c|c|c|c||}
\hline & & \multicolumn{7}{|c|}{ Efficiency of the number of GS } \\
\hline $\begin{array}{c}\text { Sub- } \\
\text { Scenario } \\
\text { Code }\end{array}$ & Input & DMU1 & DMU2 & DMU3 & DMU4 & DMU5 & DMU6 & DMU7 \\
\hline USE1 & AS & $90.6 \%$ & $80.3 \%$ & $67.9 \%$ & $49.5 \%$ & $80.2 \%$ & $54.1 \%$ & $56.1 \%$ \\
\hline USE2 & CLC & $100 \%$ & $88.9 \%$ & $92.2 \%$ & $73.1 \%$ & $84.1 \%$ & $100 \%$ & $75.3 \%$ \\
\hline USE3 & LHC & $100 \%$ & $100 \%$ & $49.6 \%$ & $100 \%$ & $21.1 \%$ & $100 \%$ & $100 \%$ \\
\hline \hline USE4 & $\begin{array}{c}\text { AS \& } \\
\text { CLC }\end{array}$ & $100 \%$ & $98.6 \%$ & $92.2 \%$ & $78.2 \%$ & $95.4 \%$ & $100 \%$ & $75.3 \%$ \\
\hline USE5 & $\begin{array}{c}\text { AS \& } \\
\text { LHC }\end{array}$ & $100 \%$ & $100 \%$ & $81.8 \%$ & $100 \%$ & $85.7 \%$ & $100 \%$ & $100 \%$ \\
\hline USE6 & $\begin{array}{c}\text { CLC \& } \\
\text { LHC }\end{array}$ & $100 \%$ & $100 \%$ & $92.2 \%$ & $100 \%$ & $84.1 \%$ & $100 \%$ & $100 \%$ \\
\hline \hline USE7 & $\begin{array}{c}\text { AS \& } \\
\text { CLC \& } \\
\text { LHC }\end{array}$ & $100 \%$ & $100 \%$ & $92.2 \%$ & $100 \%$ & $95.4 \%$ & $100 \%$ & $100 \%$ \\
\hline
\end{tabular}

Under the second set of sub-scenarios was studied the impact of two input variables on the enrollment of undergraduate students. A closer look at the efficiencies obtained for the USE4, USE5, and USE6 sub-scenarios the following is revealed:

- DMU1 and DMU6 are efficient in all three cases;

- DMU2, DMU4, and DMU7 are efficient in USE5 and USE6 sub-scenarios, while DMU2 is almost efficient in USE4 and DMU 4 and 7 stands at $75 \%$ efficiency in subscenario USE4.

- DMU3 and DMU5 experienced relative efficiencies in the range of $80-90 \%$ in all three sub-scenarios.

Performing sensitivity analysis on the variables in all three sub-scenarios provided the following recommendations in order to hike-up the relative efficiencies of the DMUs: in subscenario USE4, increase the number of USE for DMU2, DMU3, DMU4, DMU5 and DMU7 to $1500,500,1900,1150$ and 2000 students, respectively. In sub-scenario USE5, increase the number of USE for DMU3 and DMU5 to be 1300 and 1700 students, respectively. In sub-scenario USE6, increase the number of USE for DMU3 and DMU5 to 500 and 1300 projects, respectively.

Finally, for the third set of sub-scenarios which included only one sub-scenario (USE7) involving three variables. It is apparent that there were five DMUs that were efficient
(DMU1, DMU2, DMU4, DMU6 and DMU7) while the remaining two DMUs were almost $95 \%$ inefficient. For these two DMUs, it is recommended to increase the number of enrolled undergraduate students to 500 for DMU3 and 1150 for DMU5 to be fully efficient.

\subsubsection{Scenario II: Awarded Theses}

This scenario studied the production of M.Sc. and Ph.D. theses in terms of the number of academic staff (AS), number of postgraduate students (PS), and number of research scientific books (RSB). Two of the seven DMUs, by the time data was collected, had not yet awarded any theses although they have postgraduate programs and have postgraduate students enrolled in these programs. These two DMUs are DMU3 and DMU6, thus they were eliminated from further investigation in this scenario.

Again, a total of seven sub-scenarios were generated given the above aforementioned input variables, but the authors decided to settle upon six sub-scenarios. The first set included two sub-scenarios were the efficiency of the number of awarded theses (AT) is studied against only two inputs independently (AS and PS). The second set included three sub-scenarios; considering two input variables (AS and PS, AS and RSB, and PS and RSB). Finally the third set included a single model with all input variables. The results are presented in following table (Table 4).

Table 4 Relative efficiencies for the number of Awarded Theses

\begin{tabular}{|c|c|c|c|c|c|c|}
\hline \multirow[b]{2}{*}{$\begin{array}{c}\text { Sub- } \\
\text { Scenario } \\
\text { Code }\end{array}$} & \multirow[b]{2}{*}{ Input } & \multicolumn{5}{|c|}{ Efficiency of the number of ATs } \\
\hline & & DMU1 & DMU2 & DMU4 & DMU5 & DMU7 \\
\hline AT1 & AS & $78.2 \%$ & $79.4 \%$ & $40 \%$ & $77.6 \%$ & $85.9 \%$ \\
\hline AT2 & PS & $6.8 \%$ & $17.1 \%$ & $45.5 \%$ & $23.3 \%$ & $91.6 \%$ \\
\hline AT3 & AS \& PS & $78.2 \%$ & $79.4 \%$ & $79.9 \%$ & $77.6 \%$ & $91.6 \%$ \\
\hline AT4 & AS \& LST & $83.9 \%$ & $95.4 \%$ & $100 \%$ & $94.6 \%$ & $100 \%$ \\
\hline AT5 & PS \& LST & $11.9 \%$ & $63.3 \%$ & $100 \%$ & $62.9 \%$ & $100 \%$ \\
\hline AT6 & $\begin{array}{c}\text { AS \& PS } \\
\& \text { LST }\end{array}$ & $83.9 \%$ & $95.6 \%$ & $100 \%$ & $94.6 \%$ & $100 \%$ \\
\hline
\end{tabular}


From the above table, it is evident that when measuring the efficiency of the DMUs based on either the number of AS or the number of PS or both, none of the DMUs was efficient; i.e. AT1, AT2, and AT3. The results reveal that DMU7 is close to being efficient (approximately 90\%) since it has an average of 138 AS and an average 86 PS while 45 AT. With respect to sub-scenario AT1, DMU4 is the least efficient with approximately an average of one AT per six AS, while the remaining three DMUs $(1,2$, and 5) have efficiency close to $80 \%$. Thus for these four DMUs to achieve an efficiency similar to that of DMU7, it is recommended to increase the number of AT to 10 for DMU4 and 5 for DMU5, while reducing the number of AS for DMUs 1 and 2. It is evident that from the AT1, AT2, and AT3, because of having the number of AS and the number of PS but the number of AT are not adequate to justify this number of AS or number of PS when compared to each other, so no DMUs are efficient in the three sub-scenarios. Clear investigation of the technical efficiencies resulting from AT2, i.e. AT versus the number of PS, all the DMUs have very poor efficiencies when compared to that of DMU7, with the lowest being for DMU1. Comparing DMU1 to DMU7, we noticed that DMU1 has an average of 528 PS and 29 AT (an average of 1 AT per 18 PS) while DMU7 had an average of 86 PS and 45 AT (an average of 1 AT per 2 PS). For the analysis of AT2, clearly to improve the relative efficiency of the DMU1, DMU2, and DMU5 to reach the highest efficiency of DMU7, it is recommended to increase the number of AT to be 100, 39, and 12 theses respectively, and for the DMU4, to increase the number of PS.

For AT3, DMU1, DMU2, DMU4, and DMU5 have technical efficiencies of approximately $80 \%$. The relative efficiency of each DMU assumes the greater than or equal to the best efficiency among the results of AT1 vs. AT2. To improve the relative efficiency of DMU4 and DMU5 to reach the highest efficiency of DMU7, it is recommended to increase the number of AT to be 8 and 5, respectively; whereas for DMU1 and DMU2, it is not realistic to improve the relative efficiency by reducing the number of AT. Therefore, it is recommended to increase the number of AS.

On the other hand, for the analysis of AT4, AT5 and AT6, it is evident that DMU4 and DMU7 are efficient, and DMU2 and DMU5 are almost efficient in AT4 and AT6, while being 63\% efficient in AT5. Based on AT4, it is evident from the above analyses that for DMUs 1,2 and 5 the number of AT is low given the RSB of these DMUs. As mentioned above, in these two sub-scenarios DMUs 4 and 7 are efficient. In order to improve the relative efficiency of DMU1, DMU2 and DMU5 for AT5, it is recommended to increase the number of AT to be 50, 46, and 17 theses, respectively. As for AT5, it is recommended to increase the number of AT to be 50 theses for DMU1, 46 theses for DMU2 and 20 theses for DMU5. When considering all input variables in AT6, the same conclusion for AT4 and AT5 is reached, according to the highest common efficiency principal discussed earlier. Therefore, in order to improve the relative efficiency of DMU1, DMU2 and DMU5 to be efficient, it is recommended to increase the number of AT to be 50,46 and 17 theses, respectively.

\section{CONCLUSION}

This research applied the SIODEA model to investigate the relative efficiency of seven faculties of Computers and Information in the Egyptian public HEIs. The model was used to study the impact of input variables on the output of producing undergraduate students (USE) and awarded theses
(AT). Each output was presented through a scenario and for each scenario the appropriate input variables were selected. Among the input variables, two were considered to be stochastic which were the number of academic staff (AS) and number of postgraduate students (PS). The analysis revealed interesting conclusions, including the following:

- DMU4 and DMU7 were efficient in two scenarios. The data revealed that these DMUs have high potential in all aspects.

- DMU1 was efficient in scenario I and it likely approaches efficiency in scenario II;

- DMU2 turned out to be inefficient in the two scenarios. Apparently, this DMU has high potential but unfortunately is was unable to utilize its resources to efficiently produce either undergraduate students, or postgraduate theses;

- DMU3 was inefficient in scenario I and it was eliminated from the investigation in scenario II because it had not awarded any theses by the time this research was conducted;

- DMU5 was inefficient in both scenarios, but is close to reaching efficiency; and

- DMU6 was efficient in scenario I and it was eliminated from the investigation in scenario II for the same reasons mentioned for DMU3 earlier

Through the previous analyses, we noticed that the relative efficiency for DMUs considering a combination of input variables in a particular scenario assumes either the highest common efficiency value among the results from the smaller combinations of inputs (subsets - including individuals) or larger than this value.

\section{REFERENCES}

[1] Kelly, U., McNicoll, I., \& McLellan, D. (2004). "The economic impact of UK higher education institutions". University of Strathclyde.

[2] Athanassopoulos, A. D., and Shale, E. (1997). Assessing the comparative efficiency of Higher Education Institutions in the UK by the means of Data Envelopment Analysis. Education Economics, 5(2), 117-134.

[3] Chu Ng, Y., and Li, S. K. (2000). Measuring the research performance of Chinese higher education institutions: an application of data envelopment analysis. Education Economics, 8(2), 139-156.

[4] Avkiran, N. K. (2001). "Investigating technical and scale efficiencies of Australian universities through data envelopment analysis." Socio-Economic Planning Sciences, 35(1): 57-80.

[5] Abbott, M., and Doucouliagos, C. (2003). "The efficiency of Australian universities: a data envelopment analysis." Economics of Education review, 22(1): 89-97.

[6] Taylor, B. \& Harris, G., (2004), "Relative efficiency among South African universities: a data envelopment analysis". Higher Education, 47(1): 73-89.

[7] Duh, R. R., and Kuo, J.S. (2006). "Law and university efficiency: The amendment of the university law in Taiwan." Proceedings of the 2006 Joint Conference on Information Sciences.

[8] Worthington, A. C., and Lee, B.L. (2008). "Efficiency, technology and productivity change in Australian universities, 1998-2003." Economics of Education Review, 27(3): 285-298.

[9] Afonso, A., and Santos, M. (2008). "A DEA approach to the relative efficiency of Portuguese public universities." Portuguese Journal of Management Studies 13(1): 67-88. 
[10] Johnes, J., and Yu, L. (2008). "Measuring the research performance of Chinese higher education institutions using data envelopment analysis." China Economic Review, 19(4): 679-696.

[11] Agasisti, T., and Pèrez-Esparrells, C., (2010). "Comparing efficiency in a cross-country perspective: the case of Italian and Spanish state universities". High Education, 59(1): 85-103.

[12] Awadz, A. S., Ramasamy, R., Akhir, R. M., \& Loy, C. K. (2012). "Performance Evaluation of Faculties at A Private University A Data Envelopment Analysis Approach". Global Journal of Management and Business Research, 12(9).

[13] Stern, Z. S., Mehrez, A., and Barboy, A. (1994). "Academic departments efficiency via DEA." Computers and Operations Research 21(5): 543-556.

[14] Johnes, J., and Johnes, G. (1995). "Research funding and performance in UK university departments of economics: a frontier analysis." Economics of Education Review 14(3): 301-314.

[15] Lopes, A. L. M., and Lanzer, E.A. (2002). "Data envelopment analysis-DEA and fuzzy sets to assess the performance of academic departments: a case study at Federal University of Santa Catarina-UFSC", Pesquisa Operacional, 22(2): 217-230.

[16] Martin, E. (2006). "Efficiency and Quality in the Current Higher Education Context in Europe: an application of the data envelopment analysis methodology to performance assessment of departments within the University of Zaragoza." Quality in higher education, 12(1): 57-79.

[17] Köksal, G., and Nalçaci, B., (2006). "The relative efficiency of departments at a Turkish engineering college: a data envelopment analysis", Higher Education, 51(2): $173-189$

[18] Kao, C., and Hung, H.T. (2008). "Efficiency analysis of university departments: An empirical study." Omega, 36(4): 653-664.

[19] Tyagi, P., Yadav, S.P., and Singh, SP. (2009). "Relative performance of academic departments using DEA with sensitivity analysis." Evaluation and Program Planning, 32(2): 168-177.

[20] Charnes, A., Cooper, W.W. and Rhodes, E (1987) "Measuring the efficiency of decision making units". European Journal of Operational Research, 2(6): 429. 444.

[21] Banker, R. D., Charnes, A., and Cooper, W.W. (1984) "Some models for estimating technical and scale inefficiencies in data envelopment analysis." Management science, 30(9): 1078-1092.

[22] El-Demerdash, B. E., El-Khodary, I. A., and Tharwat, A A. (2013). "Developing a Stochastic Input Oriented Data Envelopment Analysis (SIODEA)" Model. International Journal, 4(4): 40-44. 